\title{
REVIEWING COMPLEXITY COSTS - WHAT PRACTICE NEEDS AND WHAT RESEARCH CONTRIBUTES
}

\author{
O. Meßerschmidt ${ }^{1,2, \bigotimes}$, T. Gumpinger ${ }^{2}$, M. Meyer ${ }^{1}$ and K. G. Mertens ${ }^{1}$ \\ ${ }^{1}$ Hamburg University of Technology, Germany, ${ }^{2}$ Odego GmbH, Germany \\ $\triangle$ ole.messerschmidt@tuhh.de
}

\begin{abstract}
Introducing more customized products causes complexity costs, which are hard to estimate and measure. Researchers and practitioners have therefore developed approaches to measure these costs. This paper reviews the current approaches and reveals a lack of a holistic view on the underlying problem and, hence, deficits to certain economic questions. We therefore suggest using the Extended Axiomatic Design (EAD) framework as an interdisciplinary model that adresses the economic consequences of variety-induced complexity.
\end{abstract}

Keywords: complexity, variety-induced complexity, cost management, product design

\section{Introduction}

Increasing customer power compels companies to continuously introduce more customized products, resulting in an ever-increasing variety of products. Since each product is distinct, it increases the internal variety by adding additional components, processes, and resources commonly regarded as complexity. This variety-induced complexity is largely inevitable, changing design and technology, which in turn leads to an increasing consumption of existing and new resources. The latter trigger costs called "complexity costs." These complexity costs are hard to estimate and measure, as they are difficult to trace back to the origin in the product (Wilson and Perumal, 2010), thus exacerbating the correct allocation of such costs to specific product variants. Subsequently, distorted cost information can impair managerial decision-making.

In our paper, we address the challenge of complexity costs. First, we survey of 33 experts from consultancies, as well as mechanical and plant engineering firms. The industry is divided on complexity costs. Our finding emphasizes firms' willingness to manage complexity costs, but also denotes the practitioners' need for guidance, transparency and to acquire data with a reasonable effort. Second, we identify a mismatch between the current approaches to measure complexity costs and the way they model the problem of variety-induced complexity. Specifically, since the current approaches adress market complexity far less, firms cannot react adequately to changing customer needs. Third, we suggest the Extended Axiomatic Design (EAD) (Mertens, 2020) as an underlying framework in order to explore the behavior of complexity costs under various product designs. The EAD incorporates engineering design theory and economic principles to link the interdependencies between customers' needs, functional requirements, components, processes, and resources. 


\section{The need to recognize complexity costs}

Research and practice constantly discuss complexity issues in terms of flexibility, performance, and, particularly, costs (Hansen et al., 2012; Bliss, 2000; Schuh et al., 2017; Ameri et al., 2008). Unfortunately, there is very little known of decision-makers' perceptions of complexity costs. We therefore surveyed 33 German and Swiss experts - 26 from mechanical and plant engineering and 7 from consulting companies - on how they deal with complexity costs, during an industrial meeting on product variety and complexity costs. Consequently, the results (Figure 1) may be biased because participants already identified the relation of product variety and costs.

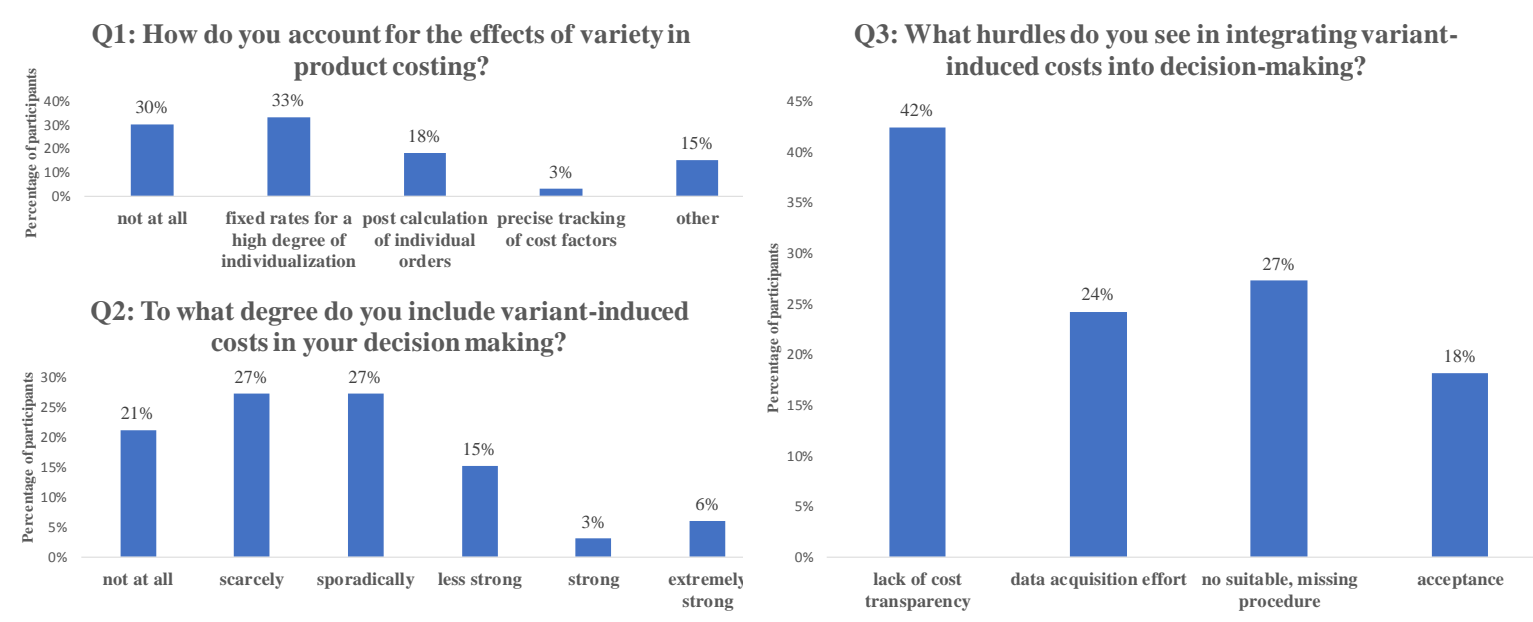

Figure 1. Results of the survey of 33 experts

The study shows that $48 \%$ of firms do not or scarcely account for product variety's cost effects in their product costing system $(\mathrm{Q} 2)$. We find that $33 \%$ of the participants use fixed complexity charges when customers request highly individualized products $(\mathrm{Q} 1)$. A group of $18 \%$ uses product variety in their post product cost calculations in order to improve their product costing for future projects. Finally, we asked the participants about current and past hurdles for measuring complexity costs (Q3). The experts mentioned the lack of complexity cost transparency in the enterprise resource planning system (42\%) and as a consequence thereof the efforts to collect cost information (24\%). A lack of suitable procedures $(27 \%)$ and the management acceptance $(18 \%)$ were mentioned as more methodological hurdles. These issues hamper management from taking variety-induced complexity's costs into account for decision making. While a lack of transparency may be due to inadequate information systems, investments in automatic data gathering may help reduce the efforts to collect data. $27 \%$ of the firms lack a practical approach to determining these costs, while the initial hurdles are possibly associated with inefficient procedures and missing acceptance among managers. The discussion of hurdles further showed that $9 \%$ of all experts use complexity costs when making decisions during product development, but do not include this information in the final product costing.

The participants agreed that the effects of product variety should be taken into account in product costing, but the majority (93\%) lacked a clear picture of how information should be measured and processed, which would enable them to calculate the complexity costs.

\section{Approaches to managing complexity costs}

\subsection{External and internal complexity}

Material and production costs are a common performance measure for evaluating cost-effectiveness in engineering; however, this measure underestimates the indirect - often hidden - complexity costs (Ripperda and Krause, 2017). The lower the direct material costs are, the greater the contribution margin. This leads to a cost optimization of single variants by introducing new, cheaper components and more specialized processes or suppliers, but ignores the indirect costs (Labro, 2004), due to increased complexity within the organization, such as longer administration processes, more inventory 
or complicated production planning. Especially in the early development stage, during which firms have a larger cost lever, but only a small amount of available information (Fixson, 2006; Skirde et al., 2016), they struggle to evaluate different product concepts' complexity costs.

This is a known issue; researchers and practitioners have therefore developed a set of approaches. Consequently, we next review those approaches that actually aim at supporting engineers to be costeffective with regard to complexity costs. Owing to complexity costs' hidden nature, we cannot evaluate their accuracy at a numeric level. In addition, we deliberately do not want to evaluate the approaches' strengths and weaknesses here, because we want to emphasize a far more fundamental problem - their incomplete system model which leads to a non-holistic view. The approaches are, however, evaluated in terms of their fit with the system in which variety-induced complexity occurs.

In doing so, we define, referring to the systems-of-systems' (SoS) principles (Maier, 1998), a market system in which the firm system is embedded. Figure 2 shows the market, including the subsystems of customers, competitors, suppliers, and firms. Within the market system, goods and services (further denoted as products) are traded between the suppliers and firms, as well as between firms and (end) customers. Further, the elements (subsystems) in the market interact, for example, competitors respond to firms' product offerings (Demski, 2008) or organizations respond to increased supplier prices. The firm system contains the elements of products, processes, and resources on a lower hierarchical level. These sub-systems reflect resources' transformation to products via processes in both production (Shephard, 1981) and design theory (Suh, 2001). Figure 2 presents the firm system embedded in a market system within the SoS context, where the external market complexity induces internal complexity in the firm system (Vogel and Lasch, 2016; Maurer, 2017).

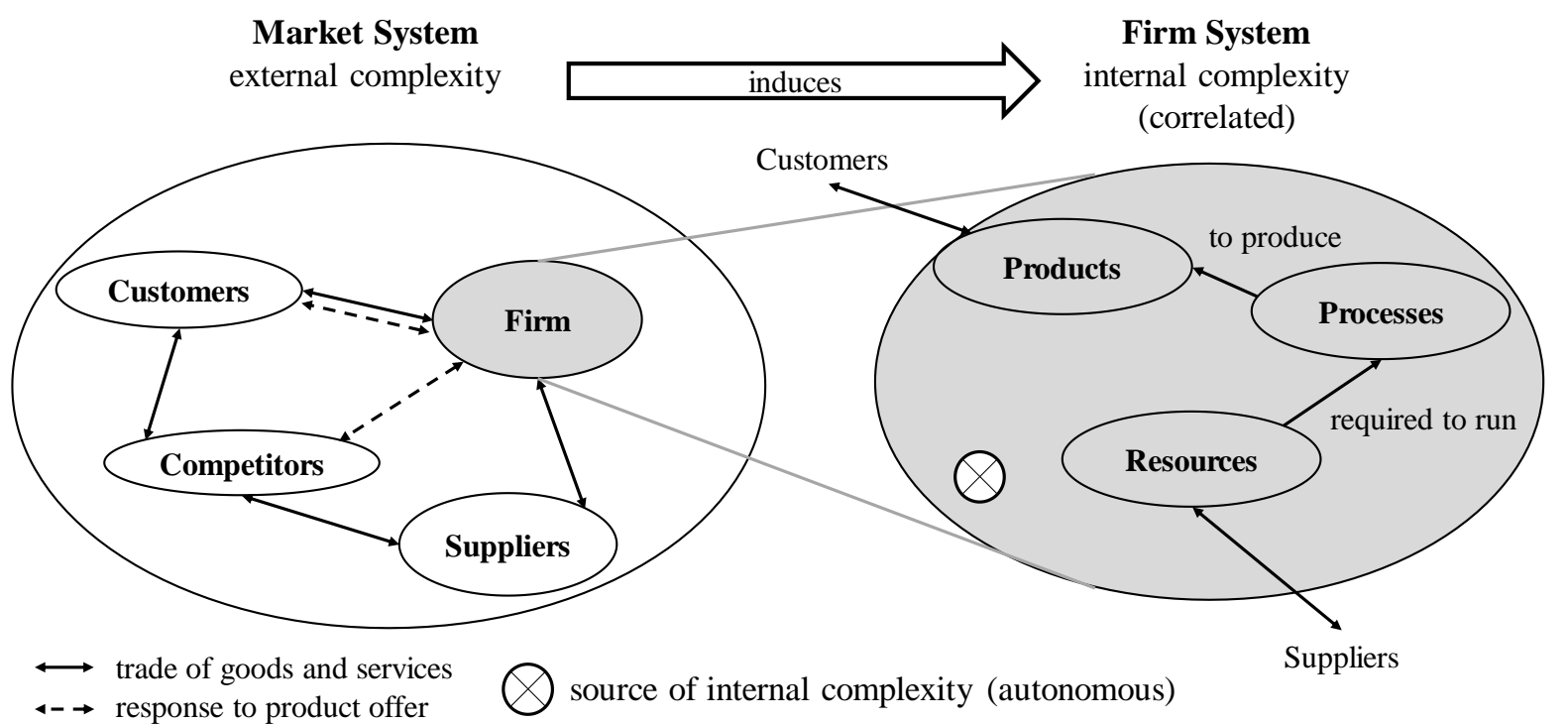

Figure 2. The market as a systems-of-systems comprising the system firm, competitors, customers, and suppliers

The market system's external complexity has a massive potential for complexity. For instance, Vogel and Lasch (2016) reviewed external complexity and concluded that society with its different languages, working methods, education levels, and legal restrictions diversifies products and therefore introduces complexity to all subsystems of the market system. Further, Kersten et al. (2006) reports on complexity in the system supplier and also mentions competitive complexity, such as search efforts (Dorman, 2014). Demand complexity in terms of uncertainty is another external complexity driver. For example, car manufacturers need to offer $10^{17}-10^{38}$ variants (Hu et al., 2008; Neff, 2016). Additionally, Vogel and Lasch (2016) identified a general market complexity in terms of market change and different markets, as well as external technological complexity, which refers to different technology standards and technology dynamics (Fuchs and Golenhofen, 2019). All these factors challenge firms and introduce complexity in the firm system also known as internal complexity (Maurer, 2017). 
We separate firms' internal complexity into two different parts. First, there is an internal correlated complexity, which is the result of external complexity. Second, there is an internal autonomous complexity, which, according to Vogel and Lasch (2016), is not induced by the market. The internal correlated complexity comprises eight main dimensions.

Bliss (2000) identifies a product portfolio complexity that describes the offered product variants and the product portfolio scope; a customer complexity defined as the number and diversity of customers; and a target complexity addressing the challenge of finding a trade-off between different targets, like between a cheap and high-quality product concept. Owing to the external technological complexity, firms have to decide if and how they need to integrate new technologies into a product (Grimm et al., 2014). Vogel and Lasch (2016) further sum that internal complexity has several other dimensions, like product development complexity, supply process complexity, service complexity, and remanufacturing complexity.

According to Vogel and Lasch (2016), the internal autonomous complexity comprises seven types. The organizational complexity describes the complexity derived from firms' organizational structure. Process complexity describes the diversity of processes due to different product variants, process chains' length, and the interdependencies. Wilson and Perumal (2010) define product complexity in terms of portfolio complexity. Other internal autonomous complexity dimensions are the production complexity (uncertainty regarding the capacity and organization of production); the planning, control, and informational complexity; the resource complexity (the variety and consumption of resources); the logistics complexity; and the sales and distribution complexity (Vogel and Lasch, 2016). We next present the existing approaches for calculating complexity costs and the way they consider the different dimensions of complexity.

\subsection{Approaches to calculate variety-induced complexity costs}

We form groups of more accounting-driven approaches on the basis of activity-based costing (ABC) and factor-based approaches, which are potentially more qualitative and use information from beyond accounting systems, to evaluate the approaches in the context.

Activity-based costing (ABC) approach, which Cooper and Kaplan (1988) first presented, is a twostage approach that first groups resources, like events, tasks, and units, into activity cost pools and then assigns their costs to product variants by using activity drivers. These activity drivers occur on different hierarchical levels, like the unit, batch, product, and facility levels (Cooper and Kaplan, 1991) and can depend on the number of repetitions, the time, and other factors (Kaplan and Cooper, 1998). Processed-based cost management (PBCM), which is a variant of the ABC approach, first groups activities into sub-processes. These sub-processes are partially or fully assigned to the main processes, where each primary process can include sub-processes in different cost centers. By means of process cost drivers, the costs of each main process are assigned to products on the basis of whether they depend on the output or not (Friedl, 2010; Horváth and Mayer, 1995).

Based on the ABC methodology, Park and Simpson (2006) developed an early-stage approach to calculate costs during the product planning by focusing on the redesigning of existing products. Using a cause-effect analysis aims at reducing the number of activities and resources that products consume to achieve cost benefits, for example, using the same housing for products even they are oversized in order to avoid a new injection mold. This approach includes the market perspective, as it checks if the chosen product platform design is aligned with the customer segments and the strategy (Park and Simpson, 2006).

Ripperda and Krause (2017) suggest a time-driven ABC (TD-ABC) method to calculate and reduce complexity costs, especially for the evaluation of modular product concepts. Based on the current product cost structure, the effect of product changes on the process times is evaluated by means of expert interviews, and the effect on the direct costs, like the material costs, evaluated by analyzing the existing data or by asking suppliers to provide data. The processes which act as the main cost drivers are identified and subsequently used to calculate the complexity costs. The PBCM approach of Schuh (1988) neglects the main processes when designing a costing system, which reduces the effort to assign sub-processes to the main processes, allows controllers to couple processes directly with resources, and solves the problem that, due to the heterogeneity of sub-process cost drivers, it is not always possible to define any or even just one cost driver for each main process (Schuh, 2005). Since 
each process now depends on just one cost driver, the processes can be arranged in chains. If measures available in the early stage, like 'number of parts' or 'number of make parts' that specify the cost drivers (Schuh and Kaiser, 1995), this approach can work as a product planning tool.

Lechner et al. (2011) propose a variety-driven ABC (VD-ABC) approach that extends the TD-ABC concept by adding the process time, inventory, and floor space equations. This approach focuses more on variety-induced logistical complexity costs. The complexity costs are computed by evaluating the three equations for each sub-process. By a summation of the costs of all non-base parts, the complexity costs are revealed (Lechner et al., 2011). Bauer et al. (2015) present an extension of the VD-ABC approach. They determine the complexity costs due to engineering changes in products, as their approach identifies the variety-inducing change drivers (VICDs), which are then linked to components and product functions. Next, the impact is tracked from a change driver's geometrical and functional perspective. For example, an affected component has functional dependencies on other components, which the VICDs also affect. Finally, the complexity costs are determined by evaluating the process times for change implementation and the running costs of each component.

Bayer (2010) introduced an ABC method that only uses processes that depend directly on product variety. Each of the chosen processes is coupled with pre-clustered complexity drivers derived from previous expert interviews. In the last step, a factor is calculated based on how much the process times, and thus the process costs, differ if one of the complexity factors changes. In contrast to Schuh (1988), who presents a top-down approach, Bayer's (2010) procedure is bottom-up.

The second group comprises different factor-based approaches. Hansen et al. (2012) analyze the gross margin's distribution across the product portfolio. They introduce Life Cycle Complexity Factors (LCCF), which illustrate the asymmetry in resource usage between products with the smallest $5 \%$ margin and those with better margins. In the next step, these factors are used to allocate the indirect costs based on the LCCFs' consumption.

Orfi et al. (2011) propose a similar approach by mapping the main complexity factors of indirect costs. Wilson and Perumal (2010) differentiate between value-adding (VA) and non-value-adding (NVA) costs. VA costs increase a product's usefulness from a customer perspective, therefore enhancing its value. In contrast, customers cannot directly perceive NVA costs. This view differs fundamentally from traditional accounting. NVA costs are assumed to be a proxy for complexity costs and are determined by subtracting the VA costs - which are defined as all the costs for raw material and the additional, directly related costs for converting them into a product - from the total costs.

Based on a current product family, Skirde (2015) suggests measuring the degree of modularity within the product family and capturing the current cost structure in a first step. Thereafter, the product family is optimized in order to increase or decrease the degree of modularity and decrease the varietyinduced complexity. The new concept's degree of modularity is then measured, and the cost structure extrapolated. The factors for the extrapolation are based on expert interviews.

\subsection{Discussion and evaluation}

Approachs' strength and weaknesses depend on the individual objective and the circumstances under which they are applied. In order to objectify the evaluation this paper focuses on the different methods' system model and the perspective towards complexity. Maurer (2017) argues that knowing the source of complexity is key to measure its impact. We follow this argument and therefore analyze how the different approaches include the different types of complexity.

The $\mathrm{ABC}$ concept assigns resources to products through activity costs. Consequently, the model only includes the resource complexity in terms of the resource quantity, and the resources' and the products' heterogeneity. However, this model ignores the fact that new variants do not necessarily require new resources or a combination of these. Variations of $A B C$ based approaches address for example process and production complexity (Lechner et al., 2011) or internal technological complexity (Park and Simpson, 2006).

Approaches that use complexity drivers, like those of Bayer (2010), Hansen et al. (2012) and Orfi et al. (2011), are more flexible with regard to capturing the different types of complexity, but less accurate regarding capturing the drivers' interaction with other elements in the overall system. Wilson and Perumal (2010) differentiate between value and non-value adding costs. Consequently, their 
approach focuses mostly on the organizational and planning, control, and information complexity in the Vogel and Lasch (2016) framework.

Summarizing the different approaches in Table 1, we identify three main groups of approaches: process-/organization-centralized (Schuh, 2005; Bayer, 2010; Wilson and Perumal, 2010), product/portfolio-centralized (Park and Simpson, 2006; Orfi et al., 2011; Hansen et al., 2012; Bauer et al., 2015; Skirde, 2015, as well as Ripperda and Krause, 2017) and logistic-/supply chain-centralized procedures (Lechner et al., 2011).

Table 1. Specification of approaches for measuring complexity costs

\begin{tabular}{|c|c|c|c|c|c|c|c|c|c|c|}
\hline & 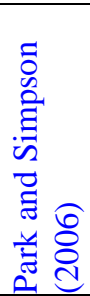 & 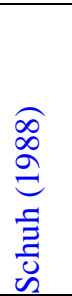 & 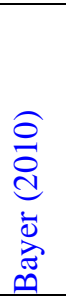 & 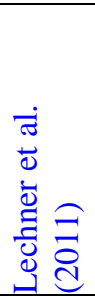 & 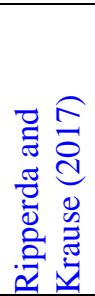 & 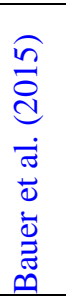 & 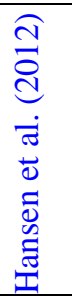 & 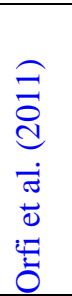 & 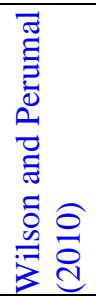 & 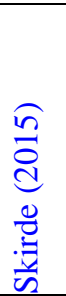 \\
\hline \multicolumn{11}{|l|}{ External Complexity } \\
\hline General market-related & $\mathrm{x}$ & & & & & & & & & \\
\hline Demand & & & & $\mathrm{x}$ & & & & & & \\
\hline \multicolumn{11}{|l|}{ Competitive } \\
\hline \multicolumn{11}{|l|}{ Supply } \\
\hline $\begin{array}{l}\text { Technological } \\
\text { (external) }\end{array}$ & $\mathrm{x}$ & & & & & & & & & \\
\hline \multicolumn{11}{|l|}{ Society } \\
\hline \multicolumn{11}{|l|}{ Internal Complexity } \\
\hline \multicolumn{11}{|l|}{ Target } \\
\hline Customer & $\mathrm{x}$ & & & & $\mathrm{x}$ & $\mathrm{x}$ & & $\mathrm{x}$ & & \\
\hline Product portfolio & & & & & & & $\mathrm{x}$ & $\mathrm{x}$ & & \\
\hline $\begin{array}{l}\text { Technological } \\
\text { (internal) }\end{array}$ & $\mathrm{x}$ & & & & $\mathrm{x}$ & $\mathrm{x}$ & $\mathrm{x}$ & & & \\
\hline Product development & $\mathrm{x}$ & & & & & $\mathrm{x}$ & $*$ & $\mathrm{x}$ & & $\mathrm{x}$ \\
\hline Supply process & & $\mathrm{x}$ & $*$ & $\mathrm{x}$ & & & $*$ & & & \\
\hline \multicolumn{11}{|l|}{ Service } \\
\hline Remanufacturing & $\mathrm{x}$ & & $\mathrm{x}$ & & & & $*$ & & & \\
\hline Organizational & & & $*$ & & & $*$ & $*$ & & $\mathrm{X}$ & \\
\hline Process & $\mathrm{x}$ & $\mathrm{x}$ & $\mathrm{x}$ & $\mathrm{x}$ & $\mathrm{x}$ & & $*$ & & & \\
\hline Production & $\mathrm{x}$ & & & $\mathrm{X}$ & $\mathrm{X}$ & & $*$ & & & \\
\hline Planning, control & & & & & & & & & $\mathrm{x}$ & \\
\hline Resource & $\mathrm{x}$ & $\mathrm{x}$ & $\mathrm{x}$ & $\mathrm{x}$ & $\mathrm{x}$ & $\mathrm{x}$ & $*$ & & & \\
\hline Logistics & $\mathrm{x}$ & $\mathrm{x}$ & $\mathrm{x}$ & $\mathrm{x}$ & $\mathrm{x}$ & $\mathrm{x}$ & $*$ & & & \\
\hline Sales \& distribution & & & $*$ & & & & $*$ & & & \\
\hline
\end{tabular}

$\mathrm{x}=$ fulfilled by the approach; $*$ = possible to integrate, but depends on the choice of factors

The analysis further shows that procedures primarily focus on internal complexity and mostly ignore the external dimensions. This is a critical factor across all approaches, because the external complexity induces the internal, correlated complexity (Vogel and Lasch, 2016; Grimm et al., 2014; Maurer, 2017). Based on this argumentation, we identify an mismatch between what the approaches aim to measure and what they do actually measure when a large source of variety-induced complexity is not modeled. What are the consequences of this mismatch? Taking fewer types of complexity into account will increase a probable error for a measurement of complexity costs. This can cause erroneous decisionmaking especially in the early stage development process. Consequently, from a comprehensive cost 
perspective, products are not perfectly designed. Promising "product architectures are never implemented " (Hansen et al., 2012, p. 1), as they appear to be more expensive from a non-complexity based perspective. Ultimately, firms cannot exploit their full potential due to the lack of complexity cost information.

\section{The Extended Axiomatic Design (EAD) to model variety-induced complexity}

\subsection{The EAD - interdisciplinary model}

To introduce a framework for assessing, among others, variety-induced complexity costs, we use the Extended Axiomatic Design (EAD) of Mertens (2020). The framework comprises elements from Suh (2001) classical axiomatic design theory and from economic modeling (i.e., Anand et al. (2019)). This framework aims to capture more aspects of complexity in a single model in order to measure complexity costs more precisely in further research. The first study by Meyer et al. (2019) applied the framework in a complexity cost context and demonstrated the calculation of costs under increasing product variety.

The EAD, presented in Figure 3, divides the SoS into subsystems (domains) of customers' needs, functional requirements, components, processes, and resources. These domains are coupled by means of domain mapping matricies (DMMs) (Danilovic and Browning, 2007) denoted as A, which contain the relevant dependencies. For instance, the product functions in the functional domain $\left(D_{F D}\right)$ are linked with the corresponding components $\left(D_{P D}\right)$ defined by $A_{F D, P D}$. The mapping of customers in $D_{C D}$ to functions is an exception here, which we will explain in 4.2. Changes in the market (customer domain), in the product design (functional and physical domain) or the processes (process domain), lead to economic consequences due to the domains' interdependencies. Defining a vector of the resource costs $(R C)$ (i.e., how much does a single resource cost per consumed unit) allows for calculating the process, components, and functional costs, as well as the product costs of each variant $(P C)$.

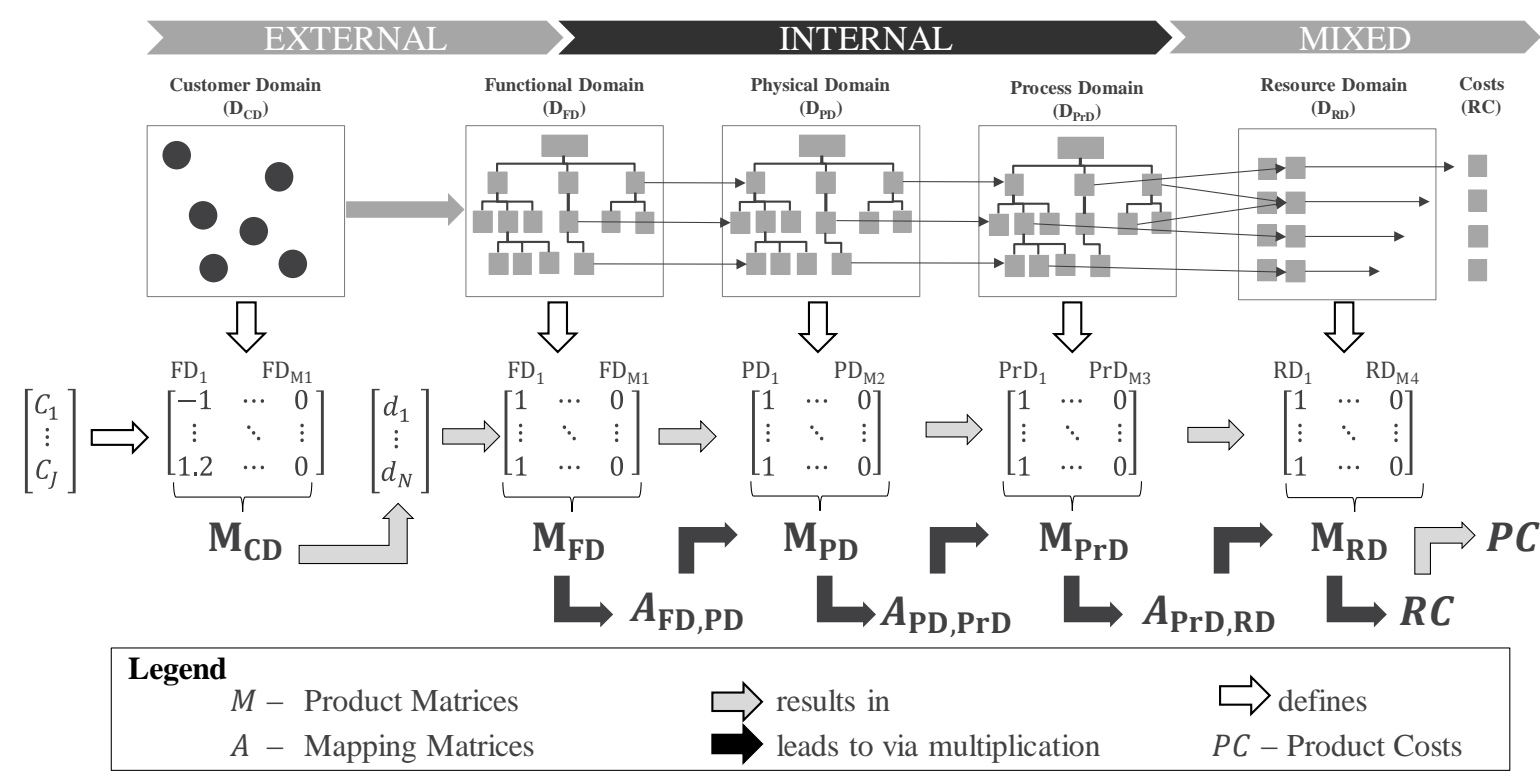

Figure 3. The Extended Axiomatic Design (EAD) with the market perspective in the customer domain, the firms' internal perspectives presented by the functional, physical, and process domain and the economic perspective represented by the resource domain

The EAD defines the customers in the market via the customer preference matrix $M_{C D}$, a potential dissatisfaction threshold, and the vector of product demand $d$. Each row of $M_{C D}$ represents the customers requirements for or against the functional requirements in the functional domain. Based on firms' product portfolio $M_{F D}$, customers choose a variant that maximizes their satisfaction. Constraining 
the portfolio by excluding features, combinations or specific products (rows in $M_{F D}$ ), customers have to choose an alternative set of functional domain elements, which results in dissatisfaction. If the dissatisfaction is below a given threshold, customers will not buy a product at all. The result is a product demand vector $d$. This market model includes the following external complexity aspects: The competitive complexity is modeled via the satisfaction threshold; a high threshold refers to market environments with competitive pressure, because customers then have many other opportunities; the society and general market complexity are included in $M_{C D}$. More homogenous patterns in $M_{C D}$ refer to similar requirements across customers or similar markets and heterogenous patterns represent customers and markets with highly individualized requirements. Replacing $M_{C D}$ as a time-dependent matrix $M_{C D}(t)$ allows us to include the external technological complexity aspect in terms of technology dynamics and integration. For example, higher market maturity and the resulting lower technology costs will change customers' preferences over time. The demand vector $d$ reflects the demand complexity in terms of the distribution, uncertainty, and time dependency. The customer complexity is included by adding new rows (more customers) or more columns (more requirements) to $M_{C D}$.

The EAD next describes the firm by means of four domains. Starting with the functional domain (product specifications), $M_{F D}$ defines the variants (rows) and product features (columns). Excluding variants (rows) in $M_{F D}$ will lead to different product portfolio complexity scenarios. In combination with the market model, the EAD allows for modeling the interaction between an offered product portfolio and customers' response. For example, excluding a variant from the product portfolio affects the demand vector, because customers can either choose an alternative product if their satisfaction is above the given threshold (the sum of the demand vector stays constant) or they can buy a competitor product (the sum of the demand vector decreases). The multiplication of $M_{F D}$ with the product architecture $A_{F D, P D}$ (Ulrich, 1994) leads to the product being represented in the physical domain as components. The product architecture represents the product development complexity, because it influences the development process decisively by defining which components must fulfill which functional requirements (Ulrich, 1994). $A_{P D, P r D}$ defines the coupling between the components $\left(M_{P D}\right)$ and the processes $\left(M_{P r D}\right)$; therefore representing the process complexity in terms of the process coupling. More feedback loops within the process domain $M_{P r D}$, which result in products having a higher process consumption, reflect the production complexity aspect.

$A_{\operatorname{PrD}, R D}$ defines the coupling of processes to resources and represents the logistic complexity. Resources needed to produce the products are defined in the resource matrix $M_{R D}$. This matrix defines the number of unique resources and how products consume them; which therefore refers to the resource complexity. The column sums of $M_{R D}$ define the total demand and its fluctuation in respect of each resource. Together with $R C, M_{R D}$ reflects the supply process complexity in terms of the demand fluctuation and the supply goods' number and prices.

The domain view allows for using the EAD as a product planning tool. Product planning starts with defining the market requirements $\left(M_{F D}\right)$. Usually, there is no knowledge of the future components, processes or resources at this point, but replacing $M_{P D}, M_{P r D}$ and $M_{R D}$ with identity matrices allow for the first assessments of variety-rich product concepts' economic consequences and robustness. Admittedly, this model does not, as yet, include all of the complexity aspects, but it allows us to combine different aspects of complexity and their interdependencies in a single framework.

\section{Conclusion and outlook}

This paper reviews current approaches to measure complexity costs. We introduce a systems-of-systems (SoS) view in the context of variety-induced complexity costs from both an external and an internal perspective. The paper compares the extent to which the existing methods cover complexity factors within this SoS view. The methods' non holistic view simplifies the problem statement to an extend that the problems' nature cannot be grasped. This reveals potential deficits in methods' application.

We suggest using the Extended Axiomatic Design (EAD), which follows the SoS structure, allows for measuring the economic consequences of different complexity aspects and for understanding their 
interdependencies. With this model we bridge the gap between product design and economic approaches. This framework fosters interdisciplinary communication and serves as a basis for further research. In future research, we will first develop a numerical simulation framework that allows for generating different markets, different product designs, and other environmental factors. Second, we will implement the drivers of complexity costs in order to understand cost effects of product variety under different conditions, which should, for example, allow us to quantify the product commonality's impact on costs. The first two steps will form the basis of the third: developing an approach that will allocate the complexity costs, depending on their cause, to single product variants. Since we will use an accounting sub-model, we will compare the developed complexity cost approach's accuracy with that of existing product costing systems, thus enabling firms to make better decisions with respect to complexity costs.

\section{References}

Ameri, F. et al. (2008), "Engineering design complexity: an investigation of methods and measures", Research in Engineering Design, Vol. 19 No. 2-3, pp. 161-179. https://doi.org/10.1007/s00163-008-0053-2

Anand, V., Balakrishnan, R. and Labro, E. (2019), “A Framework for Conducting Numerical Experiments on Cost System Design”, Journal of Management Accounting Research, Vol. 31 No. 1, pp. 41-61. https://doi.org/10. 2308/jmar-52057

Bauer, W. et al. (2015), "Complexity costs evaluation in product families by incorporating change propagation", 2015 Annual IEEE Systems Conference (SysCon) Proceedings, Vancouver, pp. 37-43. https://doi.org/ 10.1109/SYSCON.2015.7116726

Bayer, T. (2010), Integriertes Variantenmanagement. Variantenkostenbewertung mit faktorenanalytischen Komplexitätstreibern, Rainer Hampp Verlag, Mering, 2010.

Bliss, C. (2000), Management von Komplexität, Gabler Verlag, Wiesbaden, https://doi.org/10.1007/978-3-66310720-0

Cooper, R. and Kaplan, R. (1991), "Profit Priorities from Activity-Based-Costing”, Harvard Business Review, Vol. 69 No. 3, p. 130.

Cooper, R. and Kaplan, R.S. (1988). "Measure Costs Right: Make the Right Decision”, in Harvard Business Review, Vol. 5, 66th ed., pp. 96-103.

Danilovic, M. and Browning, T.R. (2007), "Managing complex product development projects with design structure matrices and domain mapping matrices", International Journal of Project Management, Vol. 25 No. 3, pp. 300-314. https://doi.org/10.1016/j.ijproman.2006.11.003

Demski, J.S. (2008), Managerial uses of accounting information, Springer series in accounting scholarship, Vol. 4, Springer, Boston. https://doi.org/10.1007/978-0-387-77451-0

Dorman, P. (2014), Microeconomics, Springer Berlin Heidelberg, Berlin, Heidelberg, https://doi.org/10. 1007/978-3-642-37434-0

Fixson, S. (2006), “A Roadmap for Product Architecture Costing”, In: Simpson, T.W., Jiao, J.R. and Siddique, Z. (Eds.), Product Platform and Product Family Design: Methods and Applications, Springer Science+Business Media LLC, Boston, MA, pp. 305-334. https://doi.org/10.1007/0-387-29197-0_13

Friedl, B. (2010), Kostenrechnung, Oldenbourg Wissenschaftsverlag, München, https://doi.org/10.1524/ 9783486710267

Fuchs, C. and Golenhofen, F. (2019), Mastering Disruption and Innovation in Product Management, Springer International Publishing, Cham, https://doi.org/10.1007/978-3-319-93512-6

Grimm, R., Schuller, M. and Wilhelmer, R. (2014), Portfoliomanagement in Unternehmen, Springer Fachmedien Wiesbaden, Wiesbaden, https://doi.org/10.1007/978-3-658-00260-2

Hansen, Mortensen and Hvam. (2012), "Calculation of Complexity Costs - An Approach for Rationalizing a Product Program", in Hansen, Rasmussen, Jřrgensen and Tollestrup (Eds.), DS 71: Proceedings of NordDesign 2012, Aarlborg, Denmark, August 22-24, 2012, The Design Society, Aarlborg.

Horváth, P. and Mayer, R. (1995), "Konzeption und Entwicklungen der Prozeßkostenrechnung”, In: Männel, W. (Ed.), Prozeßkostenrechnung, Gabler Verlag, Wiesbaden, pp. 59-86. https://doi.org/10.1007/978-3-66316322-0_7

Hu, S.J. et al. (2008), "Product variety and manufacturing complexity in assembly systems and supply chains", CIRP Annals, Vol. 57 No. 1, pp. 45-48. https://doi.org/10.1016/j.cirp.2008.03.138

Kaplan, R.S. and Cooper, R. (1998), Cost \& effect: Using integrated cost systems to drive profitability and performance, Harvard Business School Press, Boston.

Kersten, W. et al. (2006), "Complexity Management in Logistics and ETO-Supply Chains”, In: Blecker, T. and Kersten, W. (Eds.), Complexity Management in Supply Chains, Concepts, Tools and Methods, Operations and technology management, Erich Schmidt Verlag, Berlin, pp. 325-342. 
Labro, E. (2004), "The Cost Effects of Component Commonality: A Literature Review Through a ManagementAccounting Lens", Manufacturing \& Service Operations Management, Vol. 6 No. 4, pp. 358-367. https://doi.org/10.1287/msom.1040.0047

Lechner, A., Klingebiel, K. and Wagenitz, A. (2011), "Evaluation of Product Variant-driven Complexity Costs and Performance Impacts in the Automotive Logistics with Variety-driven Activity-based Costing", International MultiConference of Engineers and Computer Scientists: IMECS 2011, Hong Kong, March 1618, 2011, International Association of Engineers, Hong Kong, pp. 1088-1096.

Maier, M.W. (1998), “Architecting principles for systems-of-systems”, Systems Engineering, Vol. 1 No. 4, pp. 267-284. https://doi.org/10.1002/j.2334-5837.1996.tb02054.x

Maurer, M. (2017), Complexity Management in Engineering Design - a Primer, Springer Vieweg, Berlin, https://doi.org/10.1007/978-3-662-53448-9

Mertens, K.G. (2020), Measure and manage your product costs right: Using an extended axiomatic design for measuring and managing costs [PhD Thesis]. Hamburg University of Technology, Hamburg.

Meyer, M., Meßerschmidt, O. and Mertens, K.G. (2019), "How much does variety-induced complexity actually cost? Linking axiomatic design with cost modelling", In: Schröder, M. and Wegner, K. (Eds.), Logistik im Wandel der Zeit - Von der Produktionssteuerung zu vernetzten Supply Chains, Springer Fachmedien Wiesbaden, Wiesbaden, pp. 813-827. https://doi.org/10.1007/978-3-658-25412-4_39

Neff, M. (2016), Komplexität und Varianz - von Ursachen, Lösungen und deren Wirken, Smart Variant Con, Berlin, June 22-23, 2016.

Orfi, N., Terpenny, J. and Sahin-Sariisik, A. (2011), "Harnessing Product Complexity: Step 1-Establishing Product Complexity Dimensions and Indicators", The Engineering Economist, Vol. 56 No. 1, pp. 59-79. https://doi.org/10.1080/0013791X.2010.549935

Park and Simpson, T. (2006), "An Activity-Based Costing Method to Support Porduct Family Design", in Simpson, T.W., Jiao, J.R. and Siddique, Z. (Eds.), Product Platform and Product Family Design: Methods and Applications, Springer Science+Business, Boston, pp. 335-358. https://doi.org/10.1007/0-387-29197-0_14

Ripperda, S. and Krause, D. (2017), "Cost Effects of Modular Product Family Structures: Methods and Quantification of Impacts to Support Decision Making”, Journal of Mechanical Design, Vol. 139 No. 2, pp. 21103-1-21103-12. https://doi.org/10.1115/1.4035430

Schuh, G. (1988), Gestaltung und Bewertung von Produktvarianten ein Beitrag zur systematischen Planung von Serienprodukten, Berichte aus der Produktionstechnik, VDI-Verlag, Düsseldorf.

Schuh, G. (2005), Produktkomplexität managen: Strategien - Methoden - Tools, 2nd, revised and extended edition, Hanser, München.

Schuh, G. and Kaiser, A. (1995), "Kostenmanagement in Entwicklung und Produktion mit der Ressourcenorientierten Prozeßkostenrechnung", In: Männel, W. (Ed.), Prozeßkostenrechnung, Gabler Verlag, Wiesbaden, pp. 369-382. https://doi.org/10.1007/978-3-663-16322-0_28

Schuh, G. et al. (2017), "Product Production Complexity Research: Developments and Opportunities", Procedia CIRP, Vol. 60, pp. 344-349. https://doi.org/10.1016/j.procir.2017.01.006

Shephard, R.W. (1981), Cost and Production Functions, Springer, Berlin Heidelberg, https://doi.org/10.1007/ 978-3-642-51578-1

Skirde, H. (2015), Kostenorientierte Bewertung modularer Produktarchitekturen [Phd Thesis]. Hamburg University of Technology, Hamburg, 2015.

Skirde, H., Kersten, W. and Schröder, M. (2016), "Measuring the Cost Effects of Modular Product Architectures - A Conceptual Approach", International Journal of Innovation and Technology Management, Vol. 13 No. 04, pp. 1650017-1-1650017-23. https://doi.org/10.1142/S0219877016500176

Suh, N.P. (2001), Axiomatic design: Advances and applications, The MIT-Pappalardo series in mechanical engineering, Oxford University Press, New York.

Ulrich, K. (1994), "Fundamentals of Product Modularity", In: Dasu, S. and Eastman, C. (Eds.), Management of Design, Vol. 14, Springer Netherlands, Dordrecht, pp. 219-231. https://doi.org/10.1007/978-94-011-1390-8_12

Vogel, W. and Lasch, R. (2016), "Complexity drivers in manufacturing companies: a literature review", Logistics Research, Vol. 9 No. 1, https://doi.org/10.1007/s12159-016-0152-9

Wilson, S.A. and Perumal, A. (2010), Waging war on complexity costs: Reshape your cost structure, free up cash flows, and boost productivity by attacking process, product, and organizational complexity, McGrawHill, New York. 